\title{
TUMOUR SUPPRESSOR GENE (P53) MODULATES LIF ACTIVITY - A CAUSATIVE FACTOR FOR THE DEVELOPMENT OF NEURAL TUBE DEFECTS IN INDIA
}

\author{
SAXENA A.K. ${ }^{*}{ }^{*}$, PANDEY S. ${ }^{2}$ AND PANDEY L.K. ${ }^{2}$ \\ ${ }^{1}$ Centre of Experimental Medicine and Surgery, Faculty of Medicine, Institute of Medical Sciences, B.H.U., Varanasi-221005, UP, India. \\ 2Obestratic and Gynaecology, Paediatric Surgery, Faculty of Medicine, Institute of Medical Sciences, B.H.U., Varanasi-221005, UP, India. \\ ${ }^{*}$ Corresponding Author: Email- draksaxena1@rediffmail.com
}

Received: October 29, 2012; Accepted: November 26, 2012

\begin{abstract}
Neural tube defect (NTDs) is the most severe from of congenital malformation of central nervous system leading to infant mortality and morbidity. The most common form of NTDs is anencephaly (spina bifida) and myelomeningocele. The incidence in the population varies depending on racial/ethical variation including genetic and unknown environmental factors. The etiopathology of NTDs is still unknown between two different gene, hence present study has been designed with the aims to evaluate gene mutation between tumour suppressor gene and leukaemia inhibitory factor during organogenesis. We have collected the blood samples $(n=43)$ of clinically diagnosed NTDs with respective controls $(n=46)$ for PCR based DNA analysis to evaluate the frequency of p53 and LIF gene mutation using specific primers. Present findings reveals that highly significant differences $(\mathrm{P}<0.05)$ were observed in LIF gene using two different exons confirming p53 gene inactivation influences neural ectoderm proliferation result increased "risk factor" for the development of NTDs.
\end{abstract}

Keywords- Neural tube defect, tumour suppressor gene, leukaemia inhibitory factor.

Short Title- LIF and $\mathrm{p}^{53}$ gene interaction in NTDs

Citation: Saxena A.K., Pandey S. and Pandey L.K. (2012) Tumour Suppressor Gene (p53) Modulates LIF Activity - A Causative Factor for the Development of Neural Tube Defects in India. International Journal of Genomics and Proteomics, ISSN: 0976-4887 \& E-ISSN: 0976-4895, Volume 3, Issue 1, pp.-57-59.

Copyright: Copyright@2012 Saxena A.K., et al. This is an open-access article distributed under the terms of the Creative Commons Attribution License, which permits unrestricted use, distribution and reproduction in any medium, provided the original author and source are credited.

\section{Introduction}

Human development of neural tube defect is highly complex process. The central nervous system is initially derived from monolayer tube during the process of neurulation. Neurulation comprises two phases- primary and secondary, earlier is responsible to the folding of an induced neural plate that occurs on the dorsal side of the embryo and results in the formation of the brain and spinal cord [1-3]. Secondary neurulation is a sequential process of canalization, differentiation of neural cord and further development of spinal cord. Hence, several morphogenetic factors play an important role during embryogenesis [4].

Globally, NTDs are the most severe problem associated with congenital malformations of central nervous system (CNS) leads to causes infant morbidity and mortality. The incidence is highly variable 0.2- 3.3 per 1000 births depending on racial, ethical and geographical regions. Their incidence may be reduced the risk up to $75 \%$ after preconception supplementation of folic acid [5-6]. Since the prevalence rates of NTDs is based on several factors including nutritional problems. Incomplete developments of CNS are generating various forms of NTDs such as anencephaly or as spina bifida and myelomeningocele (MMC). These are accompanied by alterations of the axial skeleton, as well as the overlying meningovascular or dermal tissues (canalization) [7-8]. However, over $90 \%$ of the NTDs cases still have an unknown etiopathology. During normal differentiation, cell develops the ability to maintain genomic integrity by providing regulatory mechanism based on cell- cycle kinetics.

Tumor suppressor gene (p53) is also called the "guardian of genome", essential for preventing inappropriate cell proliferation by arresting cell- cycle, helps to remove damaged cells by apoptosis, maintaining genomic integrity and DNA repair during stress [910].The p53, a nuclear phosphoprotein is expressed in normal as well as malignant cells condition [11], highly conserved during evolution and its mutations causes amino acid substitutions increased instability for the development of abnormal neural tube closure including exencephaly [12-13]. Since p53 has becomes the molecule of central focus of intensive basic and clinical research and molecular mechanisms are still not well implicit but its activation increase risk factor either alone or associated with cytokines in cancer patients [14]

Leukaemia inhibitory factor (LIF) is a pleiotropic cytokine belong to IL-6 family acts as a paracrine or autocrine fashion to regulate metabolic homeostasis through binding to a heterodimeric specific glycoprotein (gp190 \& gp130), shared by several receptors of cytokines related to IL6 to maintain totipotent embryonic stem cells [1517]. The regeneration of diverse types of neural cells during development occurs through the fate of progenitor cells regulated by intrinsic or extrinsic factors. The significant of LIF gene mutation, their functional consequences and clinical impacts are still not fully understood. To understand the role of this ubiquitous cytokine, it 
becomes necessary to understand the function of LIF during organogenesis in NTDs [18]. Hence, there is considerable curiosity has been developed with the aim to determined, whether p53 gene mutation act as LIF suppressor or inducer to neural ectoderm during folding of neural tube defects. Therefore, present study becomes imperative to explore the mechanism of NTDs to understand the action of causative factors including gene-gene interactions by helping non invasive technique such as prenatal diagnose to prevent incidence of NTDs in the society.

\section{Materials and Methods}

Blood samples of NTDs $(n=43)$ were collected from the Obstetrics \& Gynaecology \& Paediatric Surgery, I.M.S., B.H.U.,Varanasi with their respective controls $(n=46)$, after written consent of patients/ attendant The criteria for inclusion of an individual were based on clinically diagnosed NTDS. The study was approved by ethical committee of the Institute. Genomic DNA was isolated from the whole blood using Bioner Kit (Korea) and samples were kept at$20^{\circ} \mathrm{C}$ till further analysis. In the present study specific primers for p53 and LIF were selected forward 5'-TGA AGT CTC ATG GAA GCC AGC. and reverse 5'-GCT CTT TTC ACC CAT CTACAG-3' while for LIF exon $3 a$ and $3 b$, forwards 5'-ACA ATT CCA GAT GCT TAC AGG G-3' and reverse 5'-GCC AAG GTA CAC GAC TAT GC3' and forwards 5'-CCC AAC AAC CTG GAC AAG CTA TG-3' and reverse 5'-CCG TAG GTC ACG TCC ACA TG-3' respectively. We have used two different PCR specific strategies for $p 53$ and LIF exon $3 \mathrm{a}$ and $3 \mathrm{~b}$ gene using specific forward and reverse primers in volume of $25 \mu$ contain $50-100 \mathrm{ng}$ of DNA, 20 pmole of each primer, $200 \mu \mathrm{M}$ of each dNTPs mix with Taq buffer $(10 \mathrm{mM}$ Tris $\mathrm{HCl}$ $\mathrm{pH} 8.3,50 \mathrm{mM} \mathrm{KCl}$ ), $3.0 \mathrm{mM} \mathrm{MgCl} 2$ and 3 unit of Taq polymerase (New England Biolab).For p53, cycling conditions were $3 \mathrm{~min}$ at $94^{\circ} \mathrm{C}$ for initial denaturation, $60^{\circ} \mathrm{C} / 30 \mathrm{sec}$ for annealing followed by 35 cycles and $72^{\circ} \mathrm{C} / 5 \mathrm{~min}$ for final extension while LIF exon $3 \mathrm{a} \& 3 \mathrm{~b}$ having same cycling conditions were $1 \mathrm{~min}$ at $94^{\circ} \mathrm{C}$ for initial denaturation, $56^{\circ} \mathrm{C} / 1 \mathrm{~min}$ for annealing followed by 35 cycles and $72^{\circ} \mathrm{C} / 78 \mathrm{~min}$ for final extension. The PCR product was separated on $1.5 \%$ agrose gel, stained with $\mathrm{Et} . \mathrm{Br}$ and bands were visualized and characterize on Gel Doc system (SR Biosystem).

\section{Results}

Table-1 showing the details finding of the p53 and LIF gene activity using polymerase chain reaction (PCR) based DNA analysis with specific amplicons to characterize mutational spectra in NTDs cases and compare the same with controls. We are able to characterize the gene mutation in terms of either complete disappearance (null) or up regulation (over expression)/down regulation (regression). To confirm the above findings the study was repeated three times. The optimal condition for amplification of DNA coding region of exon having length of the primer $279 \mathrm{bp}$ for the exploration of the p53 gene. In present study, p53 gene shows highest frequency $(30.00 \%)$ of upregulation with O.R. (4.7) at $95 \%$ C.I. (0.9$25.15)$ and in down regulation (20.00\%) with O.R.(4.2) at 95\% C.I. (0.60-33.60) were observed in NTDs cases and controls as shown in [Fig-1]. We have used two specific amplicons coding region of exon $3 a$ \& $3 b$ having length of the prime 268bp for the exploration of the LIF gene. Interestingly, LIF gene of 268 bp showing over expression (up regulation) (32.3\%), (36.6\%) with O.R. (3.2 \& 4.3) at $95 \%$ C.I. (0.90-10.8 \& 1.0-2-.3) using both exon 3a\& for 3b [Fig-2], respectively in NTDs cases. Interestingly, in three cases of NTDs
(6.90\% \& 16.0\%) showing complete disappearance (null) amplicons $268 \mathrm{bp}$ of LIF with O.R. (3.3\% \& 6.4\%) at 95\% C.I. $(0.02-0.24$ \& 0.6-16) in two different exon $3 \mathrm{a} \&$ for $3 \mathrm{~b}$, respectively and also showing the significant differences $(p<0.05)$ using chi square test.

Table 1- p53 and LIF gene mutation showing variable (\%) frequency and O.R. at 95\% C.I. between NTDs cases and controls

\begin{tabular}{|c|c|c|c|c|}
\hline Markers & $\begin{array}{l}\text { Case } \\
\% \text { frequ }\end{array}$ & $\begin{array}{l}\text { Control } \\
\text { רcy } \\
\end{array}$ & $\begin{array}{l}\text { O.R at } 95 \% \text { C.I. } \\
\text { cases vs. control }\end{array}$ & $\mathrm{p}$-value \\
\hline Up-regulation & 30 & 8.3 & $4.7(0.9-25.15)$ & $0.023^{*}$ \\
\hline Down-regulation & 20 & 5.5 & $4.2(0.60-33.60)$ & $0.073^{*}$ \\
\hline Null/Absent & 11.36 & 22.2 & $2.0(0.60-6.8)$ & 0.197 \\
\hline \multicolumn{5}{|c|}{ LIF exon3a } \\
\hline Up regulation & 32.3 & 13 & $3.2(0.9-10.7)$ & $0.028^{*}$ \\
\hline Down regulation & 41.8 & 10.8 & $5.2(1.5-18.5)$ & $0.002^{*}$ \\
\hline Null/Absent & 6.9 & 2.1 & $3.3(0.02-0.24)$ & 0.274 \\
\hline \multicolumn{5}{|c|}{ LIF exon3b } \\
\hline Up regulation & 36 & 11.4 & $4.3(1.0-20.3)$ & $0.023^{*}$ \\
\hline Down regulation & 24 & 5.7 & $5.2(0.8-41.9)$ & $0.040^{*}$ \\
\hline Null/Absent & 16 & 2.8 & $6.4(0.6-163.2)$ & $0.004^{*}$ \\
\hline
\end{tabular}

*Statistical analysis showing significant differences $p<0.05$ using $x^{2}$ square test.

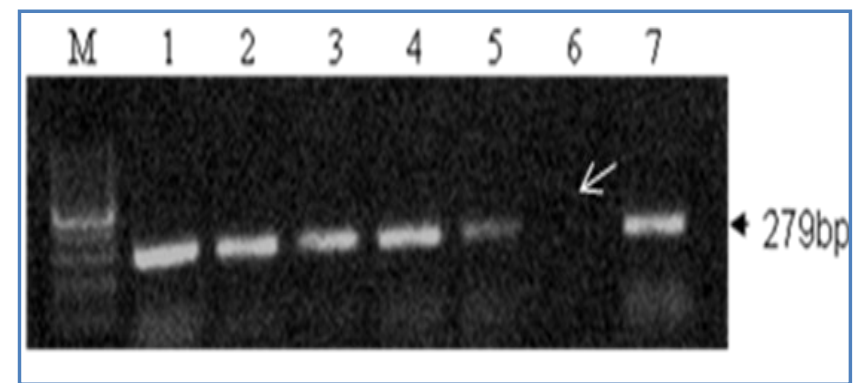

Fig. 1- PCR based DNA analysis of p53 gene showing over expression (lane-1), down regulation (lane-5) and complete disappearance of $279 \mathrm{bp}$ amplicon in lane-6 in NTDs cases

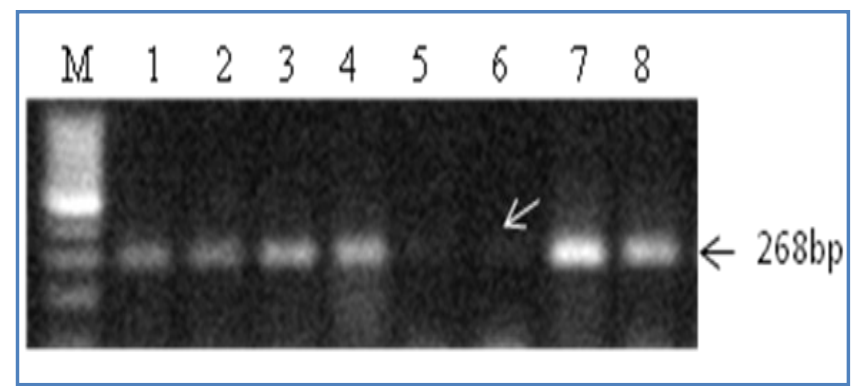

Fig. 2- PCR based DNA analysis of LIF showing over expression in lane-7, down regulation (lane-1) and complete disappearance of 268bp amplicons (lane-6) in NTDs cases.

\section{Discussion}

During differentiation of central nervous system, neural crest cells proliferation is the consequences of a combination of both extrinsic and intrinsic factors arise from the embryonic niche. The protective nature of p53 during cell damage provides genomic stability to cells. Several published studies have examined the role of p53 associated with congenital malformations including exencephaly, pre axial polydactyly and ocular abnormalities in mice [19-20]. Present study showing the variable frequency of p53 and LIF distribution in clinically classified NTDs and similar findings has also been 
reported by Hosako, et al., 2009 [20]. Hence, this unusual behaviour of p53 gene mutation during organogenesis increases "risk factor" for development of neural tube defects. Interestingly, our study of p53 gene mutation showing also significant $(p<0.05)$ difference suggesting inactivation of $p 53$ gene might have responsible for modulation of LIF activity in neural ectoderm during neuralation. Similarly, Hosako, et al, 2009 [20] also revealed that deletion of p53 in NTDs is associated with NTDs to maintain genomic integrity during neural tube closure.

Cytokine biology plays an important role during organogenesis. To identify LIF unequivocally as factor responsible for the folding of neural ectoderm either through paracrine or autocrine regulation, with or without interaction of $\mathrm{p53}$.We have observed the significant changes in the activity of LIF [Table-1], confirming by using two different sets of forward/reverse primers for such noble study that how p53 regulates LIF activity in NTDs. LIF belong to the family interleukin- 6 and little is known about regulation in NTDs, although, our study also reveals highly significant $(p<0.001)$ differences were observed in down regulation (suppress) suggesting p53 gene mutation act as suppressor during organogenesis. However, our findings confirm that p53 gene inactivation modulating LIF activity either as inducer or suppressor by up or down regulation with increase "risk factor" for the development in NTDs. The two different forms of LIF encoding signals identical in biological functions and exhibits a tissue specific distribution in such cases. The epidemiological criteria serve as useful guide lines for collecting evidence to support relationship between loss of neural function and inactivation of p53 between genetic and epigenetic pathway. Although, our findings shows a significant relationship between LIF regulatory mechanisms during neural tube closure. Such consistency and biological gradient relationship together with well recognised function of p53 makes our study more strengthen the association of LIF activity in etiopathology of NTDs during neuralation, hence we hypothesize that on the basis of our present findings that cytokines regulation during organogenesis play an essential role during cell differentiation and their transcription modulates by p53 gene inactivation increase "risk factor" for the development of NTDs.

\section{Conclusion}

In human, the exact causes of neural tube defect are still unclear but believe to be multifactorial gene-gene interaction, therefore, we conclude from the present study to across the first time association between p53 gene and LIF gene in NTDs with four possible reasons associated with such disorders:

1. p53 gene inactivation increased "risk" as an independent factor for NTDs.

2. Severity of the disease such as anencephaly is equally important for developing complications during organogenesis due to $p 53$ \& LIF gene mutation.

3. LIF gene activity confirm their association either as an independent or association with p53 gene mutation.

4. Genetic heterogeneity in population varying age, sex and belongs to different ethnic groups modulate LIF activity either due to severity of the disease or tissue specific genetic susceptibility.

Hence, plausibly hypothesize that significant association of two different genes are associated for the development of clinically diagnosed NTDs. Although, our study is small but promising to further evaluation to confirm gene- gene interaction to induce congenital malformations of central nervous system leading "Birth Defects".

\section{Acknowledgement}

Author is thankfully acknowledge to the patients who participated in the study to make it successful.

\section{References}

[1] Copp A.J., Brook F.A., Estibeiro J.P., et al. (1990) Prog. Neurobiol., 35, 363-403.

[2] Schoenwolf G.C., Smith J.L. (1990) Development, 109, 243270.

[3] Nieuwkoop P.D. (1999) Int. J. Dev. Biol., 43, 615-623.

[4] Larroche J.C. (1984) Greenfield's Neuropathology, Wiley \& Sons, New York, 385.

[5] Botto L.D., Moore C.A., Khoury M.J., Erickson J.D. (1999) N. Engl. J. Med., 341(20),1509-1519.

[6] van der Put N.M., Steegers-Theunissen R.P., Frosst P., et al. (1995) Lancet, 346(8982),1070-1071.

[7] Lemire R.J., Siebert J.R. (1990) J. Craniofac. Genet. Dev. Biol.,10, 163-174.

[8] Nathalie M.J. van der Put, Henny W.M., et al. (2001) Experimental Biology \& Medicine, 226, 243-270.

[9] Hofseth L.J., Hussain S.P., Harris C.C. (2004) Trends Pharmacol Sci., 25, 177-181.

[10]Levine A.J., Finlay C.A., Hinds P.W. (2004) Cell, 116, 67-69.

[11]Popliker A.M., Webb C.G., et al. (1985) Mol. Cell. Biol., 5, 2851 $-2855$.

[12]Sah V.P., Attardi L.D., Mulligan G.J., Williams B.O., et al. (1995) Nat. Genetics, 10, 175, 180.

[13]Migro J.M., Baker S.J., Preisinger A.C., et al. (1989) Nature, 342, 705-708.

[14]Parada L.F., Land H., Weinberg R.A., et al. (1984) Nature, 312, 649-651.

[15]Eliyahu D., Raz A., Gruss P., et al. (1984) Nature, 312, 646649.

[16]Jenkins J.R., Kudge K., C'humakov P., et al. (1985) Nature, 317, 816-818.

[17]Taga T., Kishimoto T. (1997) Annu. Rev. Immunol., 15, 797819.

[18]Kurzrock R., Estrov Z., Wetzler M., et al. (1991) Endocr. Rev., 12, 208-217.

[19]Pani L., Horal M. \& Loeken M.R. (2002) Genes and Development, 16, 676-680.

[20]Hirano T. (1998) Int. Rev. Immunol., 16, 249-284. 